\title{
Histomorphometric Study of Growth Plate Subjected to Different Mechanical Conditions (Compression, Tension and Neutralization): An Experimental Study in Lambs. Mechanical Growth Plate Behavior
}

Francisco Arriola, M.D., Ph.D., Francisco Forriol, M.D., Ph.D. and Jose Cañadell, M.D., Ph.D.

Orthopaedic Research Laboratory, Department of Orthopedics and Traumatology, Clínica Universitaria, School of Medicine, University of Navarra, Spain

Address correspondence and reprint requests to F. Forriol, Dpt COT, CUN. Avda Pio XII sn, 31008 Pamplona, Spain.

\section{SUMMARY}

We studied the morphologic effect of low mechanical stresses compression, tension and neutralization) (on the growth cartilage with an external fixator in 18 young lambs. On radiography, we only found more length in the femora subjected to tension $(\mathrm{P}<0.05)$. Bony bridges were not present, nor were there signs of altered vascularization or Ranvier's perichondral ring. Histomorphometrically, in the group subjected to tension, the germinative layer in the femur was higher $(\mathrm{P}<0.001)$ in the bones that had undergone surgery. The proliferative layer was lower in the operated tibia $(\mathrm{P}<0.001)$, and the hypertrophic layer was higher in operated tibias and femora $(\mathrm{P}<0.001)$. In the group subjected to compression, the germinative layer in the femora was higher in the operated bones $(\mathrm{P}<0.05)$; the proliferative layer of the tibia was lower $(\mathrm{P}<0.001)$ and the hypertrophic layer was higher $(\mathrm{P}<0.001)$ in both operated bones. In the neutralization group, the proliferative layer of both operated bones presented lower values $(\mathrm{P}<0.001)$ and the hyper-trophic layer was higher $(\mathrm{P}<0.001)$ than that in the control groups.

\section{KEY WORDS}

Growth plate-Chondrocytes - Histomorphometry-Biomechanics—External fixation. 


\section{INTRODUCTION}

The growth cartilage can be divided into three areas (5): the cartilaginous physis, the metaphysis, and Ranvier's zone. The functional unity of the growth cartilage constituting a column of chondrocytes in different phases (repose, proliferation, hypertrophy and death), with the consequent changes in the cell metabolism, is regulated by internal factors hormones, growth factors) and external factors of a mechanical nature $(9,12,17)$.

Mechanical conditions affect the growth cartilage $(8,10)$. Static load inhibits physeal growth whereas cyclic loads can stimulate the growth of the physeal cartilage in rat metatarsals, and the growth plate morphology follows the contours of principal tension stresses and minimum shear stresses (6). A reduction in compression is also known to cause accelerated growth $(11,19,24)$.

The present study examines the morphologic and histomorphometric effect of low mechanical stresses (compression, tension and neutralization) on the growth cartilage and its different layers.

\section{MATERIAL AND METHODS}

Eighteen 2-month-old male lambs (Ovis aries) were used, which weighed $20 \mathrm{~kg}$ at the time of the operation. After intravenous anesthesia with sodium pentobarbital (Tiobarbital $^{\circledR}$ ) at a dose of $1.5 \mathrm{mg} / \mathrm{kg}$ and fentanyl $\left(\right.$ Fentanest ${ }^{\circledR}$ ) at a dose of $0.03 \mathrm{mg}$, we fitted a unilateral external fixator (Monotube-Triax ${ }^{\circledR}$; Stryker-Howmedica, Jaquet Orthopédie, SA, Geneva, Switzerland) on the left knee joint using two $5 \mathrm{~mm}$ diameter and $20 \mathrm{~mm}$ thread length pins (Apex ${ }^{\circledR}$; Stryker-Howmedica) in the femur and two in the tibia at a distance from the growth cartilage. To maintain $5 \mathrm{~kg}$ force continuously, both in compression and tension, the unilateral external fixators were instrumented with a strain-gauge sensor. The sensor replaces a section of the lengthening bar and consists of a metal piece in which four strain gauges were placed to form a complete Wheatstone bridge measuring the axial force transmitted through the external fixator device $(8,23)$.

The lambs were divided into three groups of six animals, according to the mechanical stresses to which they were to be subjected. In the group of lambs subjected to tension (Group A), we performed a $0.5 \mathrm{~cm}$ distraction in the immediate postoperative period and the rod of the fixator was subsequently lengthened to maintained $5 \mathrm{~kg}$ tension every time until the animal was slaughtered. In the group subjected to compression (Group B), compression of $0.5 \mathrm{~cm}$ was performed and the bar of the fixator was shortened to maintained $5 \mathrm{~kg}$ compression in the fixator at every time until the animal was slaughtered. In Group C, neither tension nor compression was applied, the aim being to prevent the transmission of forces through the growth cartilage.

All animals were slaughtered 3 months after surgery by an intravenous overdose of Tiobarbital $^{\circledR}$ and 40 meq KCl. The left (operated) and right (control) femora and tibiae were extracted, and radiography performed in the anterior-posterior projection. The maximum bone length was measured using a vernier (precise to $0.05 \mathrm{~mm}$ ). 
The distal end of the femur and proximal end of the tibia were sectioned to obtain a medial portion of the lateral condyles of the femur and tibia. These were fixed for 24 hours in Bouin's solution, decalcified using polivinilpirrolidone (PVP)-ethylenediamine tetraacetic acid for 1.5 months and dehydrated by alcohols of increasing concentration. The specimens were placed in paraffin to obtain sections of $4 \mu \mathrm{m}$, which were stained using hematoxylin and eosin, Alcian blue-PAS and Masson's Trichrome.

A morphologic study was carried out on all preparations, and the proportions of the various layers and the regular or irregular arrangement of the collagen fibers and columns were noted. We studied the appearance of accessory physes, narrowing of the growth cartilage and its possible closure, bony bridges, epiphysiolyses and their location. We also looked for the presence of vascular anastomoses between the epiphysis and the metaphysis, and epiphyseal capillaries penetrating the proliferative layer.

Histomorphometric analysis of the dimensions of the layers of growth cartilage was carried out at a magnitude of $125 \mathrm{x}$ using a system of image analysis (Leica ${ }^{\circledR}$-Q500MC; Leica-Cambridge Ltd, Cambridge, UK). We measured the height of the germinative, proliferative and hypertrophic layers in five different fields in four slices from each animal (Fig. 1).

For comparison between independent groups we used a one-factor analysis of variance, with Levene's test to control for the homogeneity of variance. As an a posteriori test, we used nonorthogonal contrasts for comparisons that were of interest between particular groups. To compare paired data (operated versus control bones), we performed Student $t$ tests for paired samples within each group. We took $\mathrm{P}<0.05$ as the level of statistical significance. All the statistical analyses were performed using the SPSS package for Windows.

\section{RESULTS}

On radiography, we observed no bending, fracture or epiphysiolysis and, in the measurements taken, we only found significant differences in the case of the femora subjected to tension $(\mathrm{P}<0.05)$ (Table 1$)$. The results of the histologic and histomorphometric measurements of height of the layers of the growth plate in the femur and tibia are presented in Table 2 (also see Fig. 2).

\section{Group A}

In the histologic examination, we did not observe epiphysiolysis in the animals subjected to tension, although we did find hyperplasia of the growth cartilage with regular columns, without the presence of accessory physes or bony bridges. No anastomoses were found between the epiphyseal and metaphyseal circulation, although capillaries were seen penetrating the proliferative layer in one case. The perichondrium and periosteum remained intact in all the animals. Statistical analysis comparing the growth plate layers height in the bone that had been operated on with the control bone in each group showed that the germinative layers in the femora had highly significant differences $(\mathrm{P}<0.001)$, the values being greater in those bones that had undergone 
surgery. In the proliferative layer, there were no differences between the femora, whereas in the tibiae there were lower values in the bones that had undergone surgery $\mathrm{P}<0.001)$. In the hypertrophic layer, higher values were found in the bones that had been operated on, in both femora and tibiae $(\mathrm{P}<0.001)$.

\section{Group B}

In the animals subjected to compression, the columns of chondrocytes were found to be distorted; there were degenerate hypertrophic chondrocytes and the physeal height was reduced (Fig. 2). Bony bridges were not present, nor were there signs of altered vascularization or Ranvier's perichondral ring. The germinative layer in the tibiae was not significantly different, whereas in the femora the values were higher in the bones that had been operated on $(\mathrm{P}<0.05)$. In the proliferative layer of the tibia, lower values were found in the bones subjected to surgery than the control bones $(\mathrm{P}<0.001)$, but there were no differences in the femora. In the hypertrophic layer of both the tibiae and the femora, higher values $(\mathrm{P}<0.001)$ were found in the bones operated on than in the control bones.

\section{Group C}

The animals that wore the external fixator in a state of neutralization presented thickening of the growth cartilage, with the presence of regular columns (Fig. 2). No epiphysiolysis, bony bridges or alterations of the vascularization were present, nor was Ranvier's perichondral ring. We found no significant differences in the tibial germinative layer, whereas the femora displayed higher values in the bones subjected to surgery $(\mathrm{P}<0.05)$. In the proliferative layer of both tibiae and femora, lower values were found in the treated group $(\mathrm{P}<0.001)$. Once more, in the hypertrophic layer, greater values were found $(\mathrm{P}<0.001)$ in the treated group than in the control group, in both bones.

\section{DISCUSSION}

The radiographic results when an external fixator was fitted at minimum tension to the hind femora of 3-month-old lambs demonstrated that the bone was longer than in the control group. The response of the physis to tension in the form of small forces resulted in an increase in height owing to cellular hyperplasia $(14,20)$, although other authors (13) suggest that there is an increase in the number of columns. In our own study, we found that the increase in height was basically due to an increase in the hypertrophic layer, even though Sledge and Noble (20) describe this as also occurring in the proliferative layer.

The skeletal forces on the growth plate are difficult to determine. The growth plate is mostly curved, in the sagital and axial planes, and also the thickness and the inclination angle varies with the anatomic location (23). In our model, the distance between the pins and the different portions of the growth plate are different, and the elasticity of the pins and the mechanical properties of the soft tissues (muscles, tendons, ligaments, etc.) around the knee joint absorbed part of the forces. 
Under forces of tension, the metaphyseal irrigation is also affected $(1,2)$, producing an accumulation of chondrocytes in the hypertrophic layer without vascular supply and, therefore, without bone cells. In growth cartilage subjected to tension, the vessels have to travel further to reach the hypertrophic layer of this cartilage, which causes stretching of the vessels and a parallel reduction in their diameter and blood flow.

Debate still surrounds the effect of small forces of compression on the physis, as some authors do not believe that these forces inhibit growth $(3,21)$, although Peruchon et al. (16) were able to show that, as compression increased, growth diminished. The physis is a structure resistant to compression, which explains its potential for recovery once the mechanism of compression ceases, as has been seen when staples have been used in clinical practice. Christensen (7) pointed out that, after stapling, the physis preserved its cartilaginous structure for a period of time once growth had ceased; he observed that bony bridges did not appear until 45 days later. In most animals, growth was resumed once static compression was stopped (10). This principle is applied in clinical practice to achieve temporary cessation of growth by means of stapling (4).

Narrowing of the physis during static compression has been reported in various studies $(3,7,10,22)$. In our own experiment, we observed reduction of the proliferative zone, with highly significant differences in the tibiae and an increase in the hypertrophic zone in both the tibia and the femur, with progressive disorganization of the layers and columns of chondrocytes. The loss of morphology of the columns, and the merging of layers, were due to ceased or reduced proliferation of chondrocytes in the proliferative layer, and reduction in calcification in the hypertrophic layer as hypertrophic chondrocytes accumulate. The physis may ultimately be destroyed and epiphysiodesis may develop if compression is continued for a lengthy period of time $(7,10,18,22)$. Noguchi et al. (15) show that interruption of the vascular flow in the metaphysis inhibits reabsorption, in addition to causing a lack of calcium in the hypertrophic chondrocytes.

The formation of bony bridges in the growth cartilage is the result of vascular invasion of the injured area of the growth cartilage, as anastomoses are established between the metaphyseal and epiphyseal vessels. In the animals left in a state of neutralization, no reduction in their longitudinal growth was observed in the X-rays, although there was a decrease in the height of the proliferative layer and an increase in the hypertrophic layer in the tibiae and femora.

Despite the different mechanical conditions in the tibiae and femora of all three groups, we found an increase in the hypertrophic layer. This might be a consequence of the disturbance, the lack of joint mobility, or, although this is unlikely, the insertion of the pins of the external fixator in the metaphysis. In our view, the mechanical upset caused by any kind of stress, and the lack of joint mobility, leads to a reduction in vascular flow. In the tibiae we observed a decrease of the proliferation layer height, and in the femora an increase of the germinative height in both tension and compression groups.

\section{ACKNOWLEDGEMENTS}

The research was supported by a grant from the Echebano Foundation. 


\section{REFERENCES}

1. Alberty A, Peltonen J, Ritsilä V. Effects of distraction and compression on proliferation of growth plate chondrocytes. A study on rabbits. Acta Orthop Scand 1993;64:449-55.

2. Alberty A. Effects of physeal distraction on the vascular supply of the growth area. A microangiographical study in rabbits. J Pediatr Orthop 1993;13:373-7.

3. Blount WP, Clarke GR. Control of bone growth by epiphyseal stapling. J Bone Joint Surg Am 1949;31:464-78.

4. $\quad$ Blount WP. A mature look at epiphyseal stapling. Clin Orthop 1971;77:158-63.

5. Brighton CT. Structure and function of the growth plate. Clin Orthop 1978;136:22-32.

6. Cohen B, Chorney GS, Phillips DP, Dick HM, Mow VC. Compressive stressrelaxation behavior of bovine growth plate may be described by the nonlinear biphasic theory. J Orthop Res 1994;12:804-13.

7. Christensen NO. Growth arrest by stapling. Acta Orthop Scand (Suppl) 1973;151.

8. Forriol F, Goenaga I, Mora G, Viñolas J, Cañadell J. Measurement of bone lengthening forces; an experimental model in the lamb. Clin Biomech 1997;12:17-21.

9. Frost HM. Skeletal structural adaptations to mechanical usage (SATMU): 3. The hyaline cartilage modeling problem. Anat Rec 1990;226:423-32.

10. Gelbke $H$. The influence of pressure and tension on growing bone in experiments with animals. J Bone Joint Surg Am 1951;33:947-54.

11. Golding JSR. The mechanical factors which influence bone growth. Eur J Clin Nutr (Suppl) 1994;1:178-85.

12. Iannotti JP, Goldstein S, Kuhn J, Lipiello L, Kaplan FS. Growth plate and bone development. In: Simon SK, ed. Orthopaedic basic science. Rosemont: American Academy of Orthopaedic Surgeons, 1995:185-218.

13. Kenwright J, Spriggins AJ, Cunningham JL. Response of the growth plate to distraction close to skeletal maturity. Is fracture necessary? Clin Orthop 1990;250:61-72.

14. Noble J, Diamond R, Stirrat CR, Sledge CB. Breaking force of the rabbit growth plate and its application to epiphyseal distraction. Acta Orthop Scand 1982;53:13-6.

15. Noguchi Y, Yamaguchi T, Sugioka Y. Interruption of the metaphyseal blood supply to the growth plate inhibits accumulation of calcium in proliferative chondrocytes: an ultra-structural study. Orthop Trans 1994;17:856-7.

16. Peruchon E, Bonnel F, Baldet P, Rabischong P. Evaluation and control of growth activity of epiphyseal plate. Med Biol Eng Comput 1980;18:396-400.

17. Robertson WW. Newest knowledge of the growth plate. Clin Orthop 1990;253:270-8.

18. Siffert RS. The effect of staples and longitudinal wires on epiphyseal growth. J Bone Joint Surg Am 1956;38:1077-88.

19. Simon MR. The effect of dynamic loading on the growth of epiphyseal cartilage in the rat. Acta Anat 1978;102:176-83.

20. Sledge CB, Noble J. Experimental limb lengthening by epiphyseal distraction. Clin Orthop 1978;136:111-9.

21. Strobino L, French G, Colonna P. The effect of increasing tension on the growth of epiphyseal bone. Surg Gynecol Obstet 1952;95:694-700. 
22. Trueta J, Trias A. The vascular contribution to osteogenesis. IV. The effect of pressure upon the epiphyseal cartilage of the rabbit. J Bone Joint Surg $\mathrm{Br}$ 1961;43:800-13.

23. Viñolas J, Añorga JR, Forriol F, Goenaga I. A transducer for the measurement of forces in external fracture fixator devices. Test results. Sensors Actuators 1993;A37-38:301-6.

24. Williams JL, Vani JN, Eick JD, Petersen EC, Schmidt TL. Shear strength of the physis varies with anatomic location and is a function of modulus, inclination, and thickness. J Orthop Res 1999;17:214-22. 


\begin{tabular}{|l|c|c|c|c|c|c|}
\hline \multicolumn{7}{|c|}{ Table 1. Maximum radiographic bone length (mm) } \\
\hline & Group A, tension & Group B, compression & Group C, neutralization \\
\hline & $\mathbf{x}$ & SD & $\mathbf{x}$ & SD & $\mathbf{x}$ & SD \\
\hline Tibia (right) & 180.34 & 17.45 & 174.00 & 21.76 & 180.18 & 6.51 \\
\hline Tibia (left) & 179.40 & 13.91 & 172.58 & 20.84 & 182.80 & 6.92 \\
\hline Femur (right) & 159.20 & 14.04 & 153.75 & 18.82 & 166.40 & 5.27 \\
\hline Femur (left) & 165.64 & 17.00 & 159.35 & 25.36 & 166.24 & 2.88 \\
\hline x, mean; SD, standard deviation.
\end{tabular}

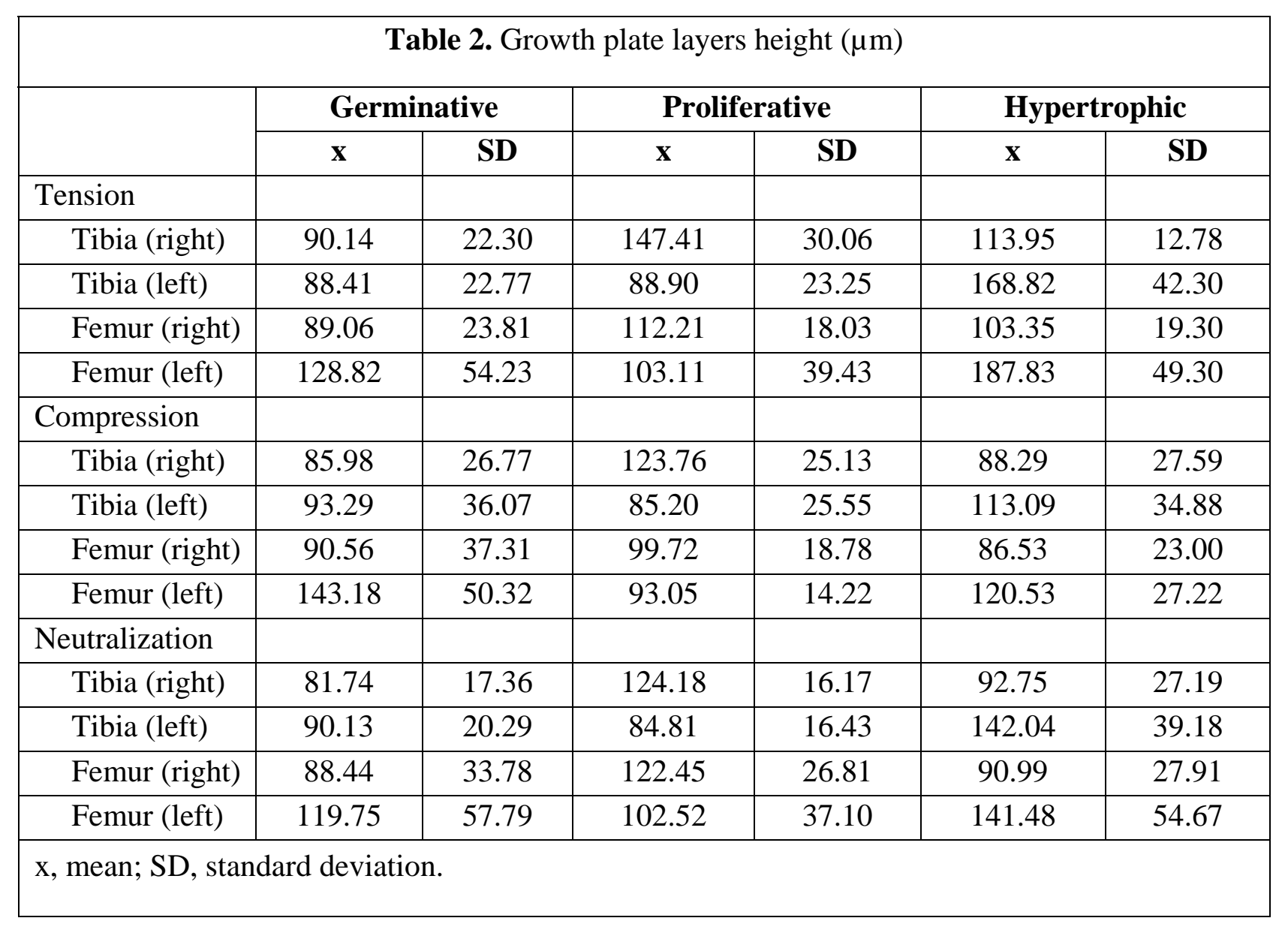




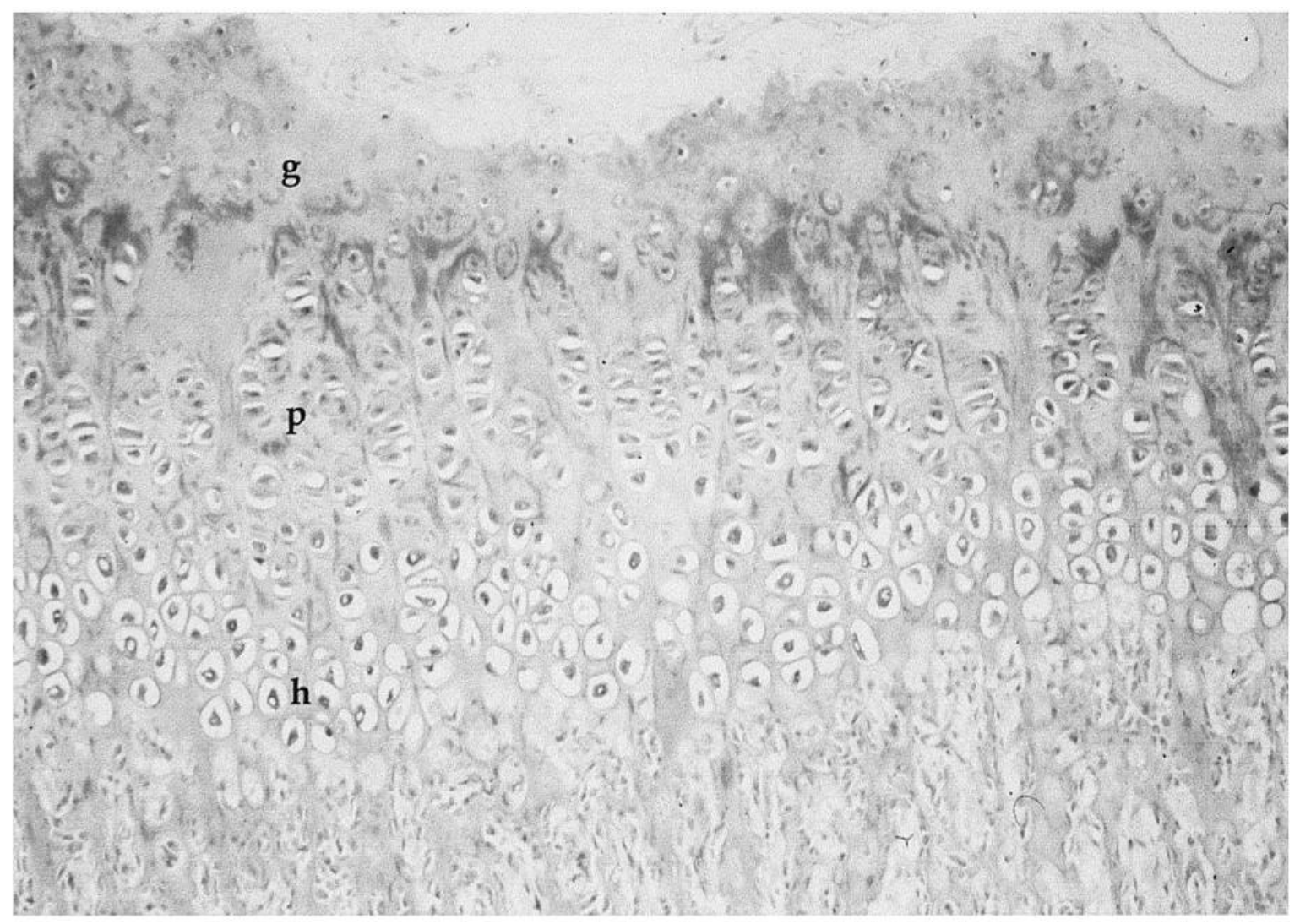

Figure 1. Growth plate (Alcian blue-PAS, x 100).

$\mathrm{g}$, Germinative layer; p, prolipherative layer; h, hypertrophic layer. 

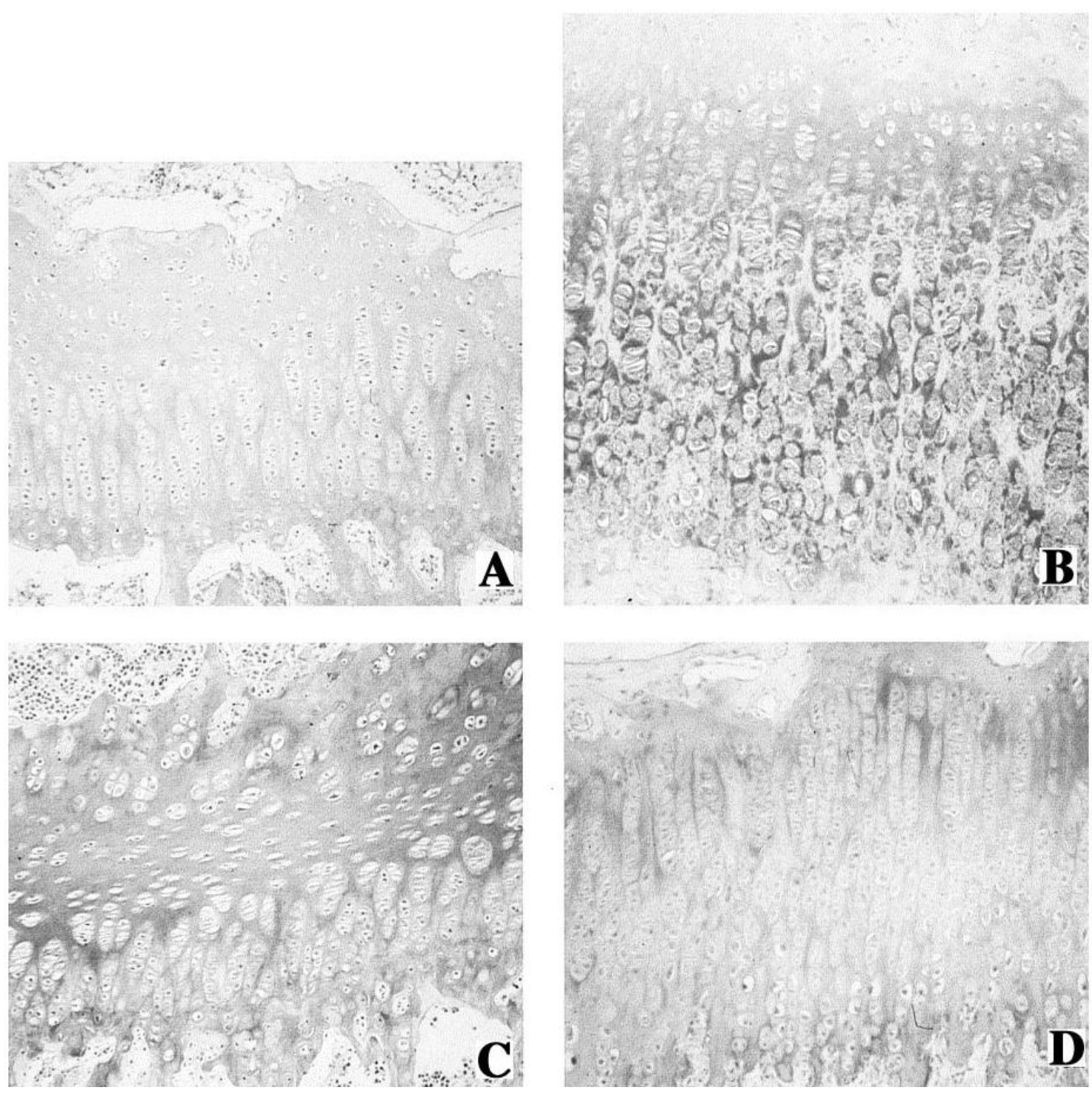

Figure 2. (A) Growth plate and (B) control subjected to tension (Group A), $0.5 \mathrm{~mm}$ distraction every 4 days during 6 weeks. The growth plate is higher than the other groups. (C) Subjected to compression (Group B), $0.5 \mathrm{~mm}$ shortening every 4 days for 6 weeks. (D) The neutralization group. (Alcian blue-PAS, x 100.) 